\title{
UPTAKE OF METALS FROM SINGLE AND MULTI-COMPONENT SYSTEMS BY Spirulina platensis BIOMASS
}

\author{
POBIERANIE METALI Z UKŁADÓW JEDNO- I WIELOSKŁADNIKOWYCH \\ PRZEZ BIOMASE Spirulina platensis
}

\begin{abstract}
Spirulina platensis biomass is widely applied for different technological purposes. The process of lanthanum, chromium, uranium and vanadium accumulation and biosorption by Spirulina platensis biomass from single- and multi-component systems was studied. The influence of multi-component system on the spirulina biomass growth was less pronounced in comparison with the single-component ones. To trace the uptake of metals by spirulina biomass the neutron activation analysis was used. In the experiment on the accumulation the efficiency of studied metal uptake changes in the following order: $\mathrm{La}(\mathrm{V})>\mathrm{Cr}(\mathrm{III})>\mathrm{U}(\mathrm{VI})>\mathrm{V}(\mathrm{V})$ ( single-metal solutions) and $\mathrm{Cr}(\mathrm{III})>\mathrm{La}(\mathrm{V})>\mathrm{V}(\mathrm{V})>\mathrm{U}(\mathrm{VI})$ (multi-metal system). The process of metals biosorption was studied during a two-hour experiment. The highest rate of metal adsorption for single-component systems was observed for lanthanum and chromium. While for the multi-component system the significant increase of vanadium and chromium content in biomass was observed. In biosorption experiments the rate of biosorption and the $K_{d}$ value were calculated for each metal. Fourier transform infrared spectroscopy was used to identify functional groups responsible for metal binding. The results of the present work show that spirulina biomass can be implemented as a low-cost sorbent for metal removal from industrial wastewater.
\end{abstract}

Keywords: biosorption, bioaccumulation, chromium, FT-IR spectroscopy, lanthanum, vanadium, uranium, neutron activation analysis, Spirulina platensis

\section{Introduction}

The presence of various metal ions in water bodies, arising from the discharge of industrial wastewater and other anthropogenic activities is one of the most important environmental issues due to high metal toxicity and accumulation in food chain [1]. Conventional techniques used for the removal of metal ions such as precipitation, oxidation, ion-exchange, electrochemical treatment have significant disadvantages

\footnotetext{
${ }^{1}$ Joint Institute for Nuclear Research, Joliot-Curie Str., 6, 141980 Dubna, Russia

${ }^{2}$ Horia Hulubei National Institute for R\&D in Physics and Nuclear Engineering, 30 Reactorului Str. MG-6, Bucharest - Magurele, Romania

${ }^{3}$ Frumkin Institute of Physical Chemistry and Electrochemistry, Russian Academy of Sciences, Moscow, 31 Leninsky prospect, Moscow GSP-1, 119071 Russia

${ }^{4}$ Institute of Microbiology and Biotechnology of the Academy of Science of Moldova, 1, Academiei Str., 2028 Chisinau, R. Moldova

"Corresponding author: zinikovskaia@mail.ru
} 
including high cost, incomplete metal removal, high energy consumption, generation of large volume of sludge that require special disposal [2, 3]. Consequently, there is a necessity in alternative methods, which can overcome all these problems and treat the wastewater in an appropriate way [4]. The use of microorganisms for the removal of toxic pollutants and for the recovery of valuable elements from wastewaters is one of the most recent developments in environmental technology [2].

Biosorption and bioaccumulation have emerged as a cost-effective and efficient alternative to traditional techniques of metal removal [4]. Biosorption is a metabolically-passive process resembling conventional adsorption or ion exchange. It is a process of concentration of sorbate (metals) on the surface of biological matrix. The process is simple in operation, cheap, with a minimal amount of sludge generation and can be efficiently applied for diluted industrial effluents. As biosorbents can be used materials collected directly from the environment and/or wastes of different biotechnological processes. Biosoption is influenced by several factors such as: type and amount of the biomass, $\mathrm{pH}$, temperature, metal concentration, presence of competing ions in solution. Since biosorption is an extracellular process the main role in metal binding belongs to the chemical functional groups of the cell wall (carboxyl, phosphonate, amine, hydroxyl, etc) [5-7].

Bioaccumulation is a process, which deals with living organisms and includes two-stages: biosorption and intracellular metal uptake with further oxidation or reduction, microprecipitation or incorporation in cell structures. Thus, in bioaccumulation more binding sites for the pollutant are available and lower residual concentrations can be reached. At the same time bioaccumulation is a very complex process and depends on several factors especially on the presence of pollutants in the growth medium which can inhibit the growth of cells and also bioaccumulation itself. There is a severe limitation of the process, as high load of pollutants may interrupt organism's metabolism, resulting in its death $[5,6]$. Biosorption and bioaccumulation are mainly used for the removal of metal cations from the solutions.

A large number of species of microorganisms has been investigated for their ability to remove toxic metals by bioaccumulation, biosorption, bioprecipitation, and other processes [8-10].

The major challenge of the preliminary stage of the present work was to identify the microorganisms for metal uptake from extremely large pool of readily available and inexpensive biomaterials. Among the microorganisms, cyanobacteria are of great interest for metal removal. The effectiveness of cyanobacteria application in aforementioned processes consists in their ubiquitous nature, existing cost-effective technologies for their cultivation, optimal surface/volume ratio, the large number of highly specific binding groups on the cell wall and by the efficient uptake and retention of metals.

Numerous investigations have shown that Spirulina platensis can be efficiently applied as a bioaccumulator and sorbent of different metals and radioactive ions [11-14]. From literary sources, it can be seen that great attention is given to processes of metal removal with use of biological objects from single component systems [15]. However, wastewaters represent complex solutions, which contain different chemical compounds. Consequently, there can be significant differences in the efficiency of metal removal from single- and multi-component systems

The aim of the present study was to investigate the process of lanthanum, vanadium, uranium and chromium ions uptake from single component and multi-component batch 
systems by cyanobacteria Spirulina platensis (S. platensis). The metal uptake by biomass was traced using high sensitive technique - neutron activation analysis, which permits simultaneous determination of more than 30 elements in biomass.

\section{Materials and methods}

\section{Materials}

\section{Reagents}

For the analysis Merck reagents: uranyl nitrate salt, sodium vanadate, lanthanum nitrate, and chromic potassium sulphate of analytical grade were used.

\section{Biomass}

To carry out the experiment, algological pure culture of S. platensis CNM-CB-02 strain from the National Collection of Non-pathogenic Microorganisms (Institute of Microbiology and Biotechnology, Academy of Sciences of Moldova) was used. The cultivation of spirulina was carried out in a bioreactor with a volume of $30 \mathrm{dm}^{3}$ in the Zarrouk nutritive medium at a temperature of $25-30^{\circ} \mathrm{C}$, illumination $37-55 \mu$ moles of photons $/ \mathrm{m}^{2} / \mathrm{s}, \mathrm{pH} 9.5-10$ and at constant mixing. The cultivation of the S. platensis cells was conducted for 10 days. After cultivation S. platensis biomass was separated from the nutritive medium by vacuum filtration on track membrane filter with $2 \mu \mathrm{m}$ pores.

\section{Single-component system}

In the first type of experiment to study metal ions accumulation metal salts in concentrations $100 \mathrm{mg} / \mathrm{dm}^{3}$ were mixt with the spirulina culture (first day of cultivation) in $100 \mathrm{~cm}^{3}$ of Zarrouk nutrient medium. The cyanobacteria were grown until reaching a stationary phase (10 days after inoculation). During the first experiment biomass concentration was determined spectrophotometrically on the basis of calibration curve.

In the second type of experiment to determine the biosorption of metal cations by cyanobacteria the biomass cultivated for 10 days in Zarrouk medium and separated from the medium (by vacuum filtration on track membrane filter with $2 \mu \mathrm{m}$ pores) was used. $100 \mathrm{mg}$ of wet $S$. platensis cells were suspended in $10 \mathrm{~cm}^{3}$ of $0.9 \% \mathrm{NaCl}$ with the same metal concentrations in tephlone vessels (on a rotary shaker set at $100 \mathrm{rpm}$ ). The dynamics of the adsorption processes was studied during 2 hours. The samples were obtained at 5, 15, 30, 60 and 120 minutes. At the end of all experiments, the spirulina biomass was filtered using the track membrane filter and dried till constant weight. All experiments were performed in duplicate.

As a control for all experiments the $S$. platensis biomass grown in the standard Zarrouk nutritive medium (without any metal additions) was used.

\section{Multi-component system}

Solutions containing four selected elements concentrations were prepared with the same salts mentioned above. The scheme of experiments was the same as for the single-component experiment. 


\section{Methods}

\section{$U V$-VIS Spectrometry}

To determine total biomass concentration during bioaccumulation experiment every day $2 \mathrm{~cm}^{3}$ of obtained suspension were measured on the Varian Cary 4000 spectrophotometer at the wavelength $650 \mathrm{~nm}$. The amount of biomass was calculated according to the calibration curve.

\section{Neutron activation analysis (NAA)}

Neutron activation analysis (NAA) is an analytical technique for qualitative and quantitative determination of elements based on the measurement of characteristic radiation from radionuclides formed directly or indirectly by neutron irradiation of the material. NAA advantages include high sensitivity, good selectivity, good accuracy, independence of matrix effects, nondestructive nature; possibility of simultaneously determining a large number of elements; independence of the results of the form of chemical compounds, easy procedure for samples preparation. Since NAA requires access to a nuclear reactor, the method is less widely applied than other analytical techniques for elemental analysis. NAA has been found to be very useful in the determination of trace and minor elements in biological samples [16, 17].

To determine the elemental composition of S. platensis biomass, neutron activation analysis at the pulsed fast reactor IBR-2 (FLNP JINR, Dubna) was applied. The description of the irradiation channels and the pneumatic transport system REGATA of the IBR 2 can be found elsewhere [22]. To determine short-lived isotopes, the samples were irradiated for 3 min under a thermal neutron fluency rate of approximately $1.6 \cdot 10^{13} \mathrm{n} \mathrm{cm}^{-2} \mathrm{~s}^{-1}$ and measured for $15 \mathrm{~min}$. In the case of long-lived isotopes the samples were irradiated for 4 days under a resonance neutron fluency rate of approximately $3.31 \cdot 10^{12} \mathrm{n} \mathrm{cm}^{-2} \mathrm{~s}^{-1}$, repacked and measured using high-purity germanium detectors twice (after 4-5 days and 20-23 days of decay). The lanthanum content in the samples was determined by $\gamma$-line with the energy of $1596.5 \mathrm{keV}$ of isotope ${ }^{140} \mathrm{La}$, vanadium by $\gamma$-line with the energy of $1434.1 \mathrm{keV}$ of isotope ${ }^{52} \mathrm{~V}$ chromium by $\gamma$-line with the energy of $320.1 \mathrm{keV}$ of isotope ${ }^{51} \mathrm{Cr}$, and uranium by $\gamma$-line with the energy of $106.1 \mathrm{keV}$ of isotope ${ }^{239} \mathrm{~Np}$. The quality was assured by the use of the certified reference materials, which were irradiated in the same conditions with samples. The NAA data processing and determination of element concentrations were performed using the software developed in FLNP JINR.

\section{Fourier Transform Infrared Spectroscopy (FT-IR)}

FT-IR spectroscopy was used to confirm the presence of the functional groups in the samples of $S$. platensis and to observe the chemical modification after heavy metal adsorption. Infrared spectra were recorded in the $4000-550 \mathrm{~cm}^{-1}$ region using a Thermo Nicolet Nexus 4700 FT-IR Spectrometer.

\section{Results and discussion}

The cyanobacterium $S$. platensis is a well-studied object widely used for physiological, biochemical, genetical, biotechnological, and ecological purposes. Different technologies for its growing and obtaining of various pharmaceuticals have already been developed. Spirulina's bioaccumulation ability serves as a basis for the obtaining of metal containing 
biomass. The strain used in the present study, Spirulina platensis CNM-CB-11, is considered to be a good accumulator of different metal (iron, zinc, selenium, chromium, copper, nickel, cadmium, uranium, etc) $[11,18]$. The accumulated metals are distributed mainly in amino acids, oligopeptides, proteins, lipids, and carbohydrates fractions of biomass [11]. The biochemical composition of the biomass is the following: proteins $65.8 \%$, carbohydrates $-9.3 \%$, lipids $-5.2 \%$, phycobiliproines $-14.0 \%, \beta$-caroten $-0.3 \%$. The main bioactive compounds are glutamic acid 9.6\%; $\gamma$-linolenic - 1.4\%; sulfated polysaccharides $-5.0 \%$, phosfatidylinositol - $0.7 \%$, and phosfatidylcholine $-1.9 \%$. In stationary culture at the end of the life cycle the biomass quantity reaches values of $1.5-1.6 \mathrm{~g} / \mathrm{dm}^{3}$.

In the first type of experiments, viable spirulina cells were used and metal solutions were added as a component of the nutritive medium on the first day of cultivation. The dynamics of spirulina biomass growth under metal loading is presented on Figure 1.

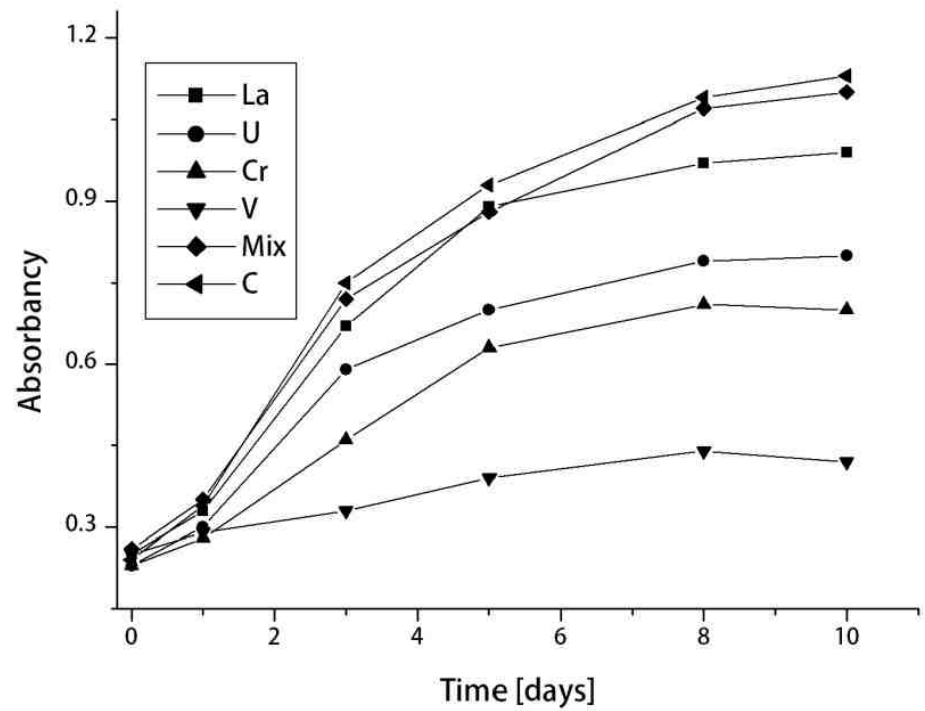

Fig. 1. Dynamics of spirulina biomass growth (La - medium with lanthanum salt, $100 \mathrm{mg} / \mathrm{dm}^{3} ; \mathrm{U}$ - with uranium salt, $100 \mathrm{mg} / \mathrm{dm}^{3} ; \mathrm{Cr}$ - chromium salt, $100 \mathrm{mg} / \mathrm{dm}^{3} ; \mathrm{V}$ - vanadium salt, $100 \mathrm{mg} / \mathrm{dm}^{3}$; Mix - four salt each in a concentration of $100 \mathrm{mg} / \mathrm{dm}^{3} ; \mathrm{C}$ - control sample)

The investigation of $S$. platensis growth under metal loading showed the lowest rate of biomass growth at vanadium loading. The highest rate was observed at the addition of metal mixture and it was almost equal to control sample. According to the influence of the elements on the spirulina they can be placed in the following line: $\operatorname{mix}>\mathrm{La}(\mathrm{V})>\mathrm{U}(\mathrm{VI})>$ $\mathrm{Cr}(\mathrm{III})>\mathrm{V}(\mathrm{V})$.

The results obtained for biomass growth were confirmed by NAA. Figure 2 presents the results of metal uptake by biomass for single and multi-component systems. As it can be seen from the obtained data the highest rate of accumulation was observed for lanthanum and chromium from both types of systems. The amount of lanthanum and chromium in the biomass after 10 days of cultivation in single-component systems increased from $0.1 \mu \mathrm{g} / \mathrm{g}$ to $15 \mathrm{mg} / \mathrm{g}$ and from $6 \mu \mathrm{g} / \mathrm{g}$ to $14.9 \mathrm{mg} / \mathrm{g}$, respectively. In the 
multi-component system after 10 days of cultivation the content of lanthanum in biomass reached the value of $7.1 \mathrm{mg} / \mathrm{g}$ and of chromium $-10.6 \mathrm{mg} / \mathrm{g}$.

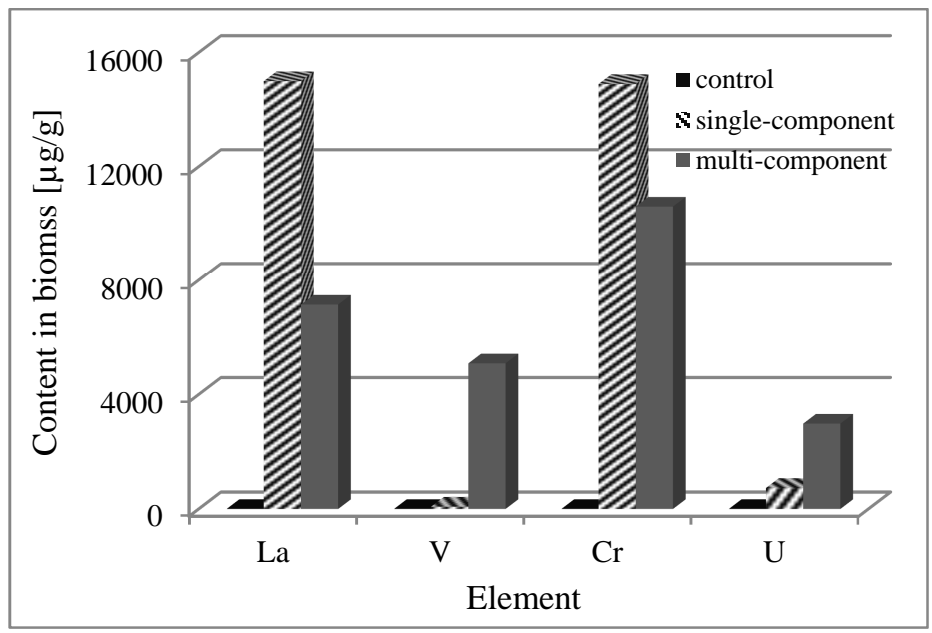

Fig. 2. La, V, Cr, and U uptake by spirulina biomass during bioaccumulation process

$\mathrm{Cr}(\mathrm{III})$ as an essential microelement can be involved in the biochemical processes of a cell. High rate of chromium accumulation can be explained by its incorporation in cell structures [1]. In case of lanthanum, the mechanism of its penetration into the cell is not well studied. In Merroun et al [19] work it was shown that after interaction of lanthanum with bacteria Myxococcus xanthus lanthanum was fixed in the cell wall and in the cytoplasm. Other studies revealed lanthanum fixation in the cell wall and in the periplasmic domain. It is suggested that the main role in lanthanum binding belongs to phosphate groups and the phosphoryl residues of phospholipids, lipopolysaccharides, nucleic acids, polyphosphates, etc. [20].

Addition of vanadium salt to nutrient medium leads to increase of its content in biomass from 0.01 to $83 \mu \mathrm{g} / \mathrm{g}$. In the multi-component system, the degree of vanadium accumulation was much higher, and reached the value of $5085 \mu \mathrm{g} / \mathrm{g}$. Vanadium is a structural and electronic analog of phosphorus and it can inhibit many phosphate-metabolizing enzymes [21], which determines its toxicity for cells. It is remarkable that the vanadium toxicity is manifested in a single-component system. Determining the optimal concentrations for obtaining vanadium enriched spirulina biomass Vasilieva et al [23] have shown that the concentration of vanadium in medium should be $1.5 \mathrm{~g} / \mathrm{dm}^{3}$. The results obtained in the present study reveal that to obtain biomass enriched with vanadium it is preferable to apply multi-component systems, in which vanadium accumulation is more efficient.

In the accumulation study, the content of uranium in biomass in comparison with native biomass increased from 0.06 to $735 \mu \mathrm{g} / \mathrm{g}$. Uranium has no biological function and is known to be toxic to microorganisms. Some reports have shown the binding of uranium ions to proteins and inhibition of microorganism growth [24]. Although there is a possibility for extracellular reduction of $U(V I)$ to $U(I V)$, which prevents its penetration into the cell and preserves cell's viability. Uranium accumulation in microbial cells occurs 
mostly through passive diffusion and it can be concentrated in vacuoles. Kalin and co-authors [25] have emphasized two mechanisms of uranium interaction with microorganisms: ion exchange or co-precipitation and complexation with cell biomolecules.

Usually, the uptake of metals by microorganisms from single metal systems is higher in comparison with a multi-component one [26]. The metals combination in multi-component system can have both synergistic and antagonistic effects. In case of antagonistic metals interaction in a multi-metal system the specific binding sites available for single-metal uptake are reduced, and the degree of metal binding depends of its electronegativity and ionic radius $[27,28]$. In the present study the antagonistic effect of uranium and vanadium on the lanthanum and chromium uptake was observed. Thus, the accumulation of lanthanum and chromium decreased in comparison with single-metal systems: twice for lanthanum and 1.5 times for chromium. Consequently, in the studied multi-component system the synergistic relationship between vanadium and uranium was remarked. The content of vanadium increased by 61 times and of uranium by 4 times in comparison with single component systems. Synergism in the metal interaction is manifested by reduction of metal ions toxicity and the increase of metal uptake [29].

Thus, the native biomass of spirulina has shown to be suitable for metal removal from single and complex solution, particularly for lanthanum and chromium. However, for large-scale application accumulation of metals by spirulina culture is not profitable because of the high price of the process, which involves several procedures, including ensuring the conditions of biomass growth.

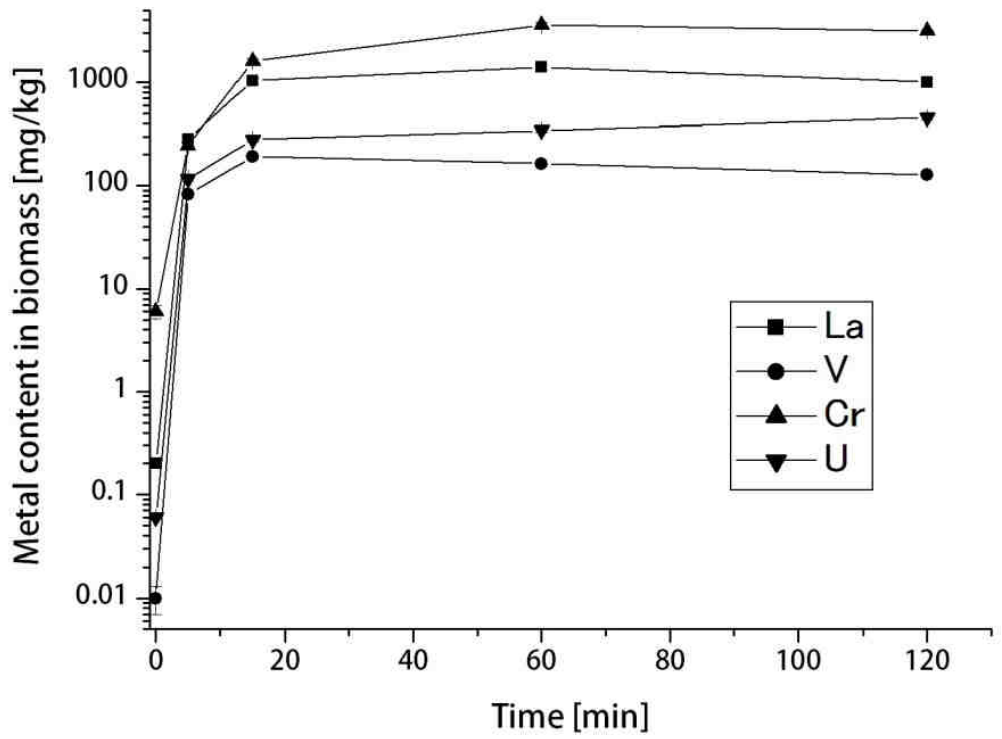

Fig. 3. La, V, Cr, and U concentration in S. platensis biomass as a function of contact time (data for single component systems)

The aim of the second type of experiment (biosorption) was to determine the optimal time for attaining the sorption equilibrium with the given metal concentrations. The first 
phase of interaction was rapid, high efficiency of uptake for all elements was observed in the first $15 \mathrm{~min}$ of sorbent-sorbate interaction (Fig. 3).

For lanthanum and chromium the maximum level of metal in the spirulina biomass was reached in about $60 \mathrm{~min}$ of contact: 1.4 and $3.5 \mathrm{mg} / \mathrm{g}$, respectively. A continuous increase of uranium content in biomass was marked (up to $455 \mu \mathrm{g} / \mathrm{g}$ ). It is well known that in the rapid phase the metal ions are mainly bound to microorganism's cell wall functional groups. The slow phase is connected with metal intracellular accumulation [29]. The increase of uranium concentration can be explained by its intracellular uptake. The lowest rate of vanadium ions adsorption $(128 \mu \mathrm{g} / \mathrm{g})$ is related to its toxicity for spirulina biomass.

As in case of single element systems in a multi-component system (Fig. 4) the metal uptake occurred in two stages. The behavior of uranium and lanthanum was similar to the single component systems with the content increase from 0.1 to $1050 \mu \mathrm{g} / \mathrm{g}$ for lanthanum and from 0.06 to $595 \mu \mathrm{g} / \mathrm{g}$ for uranium, respectively. The amount of adsorbed chromium increased 1.7 times in comparison with the single metal system, and significant increase of vanadium content up to $1050 \mu \mathrm{g} / \mathrm{g}$ was observed.

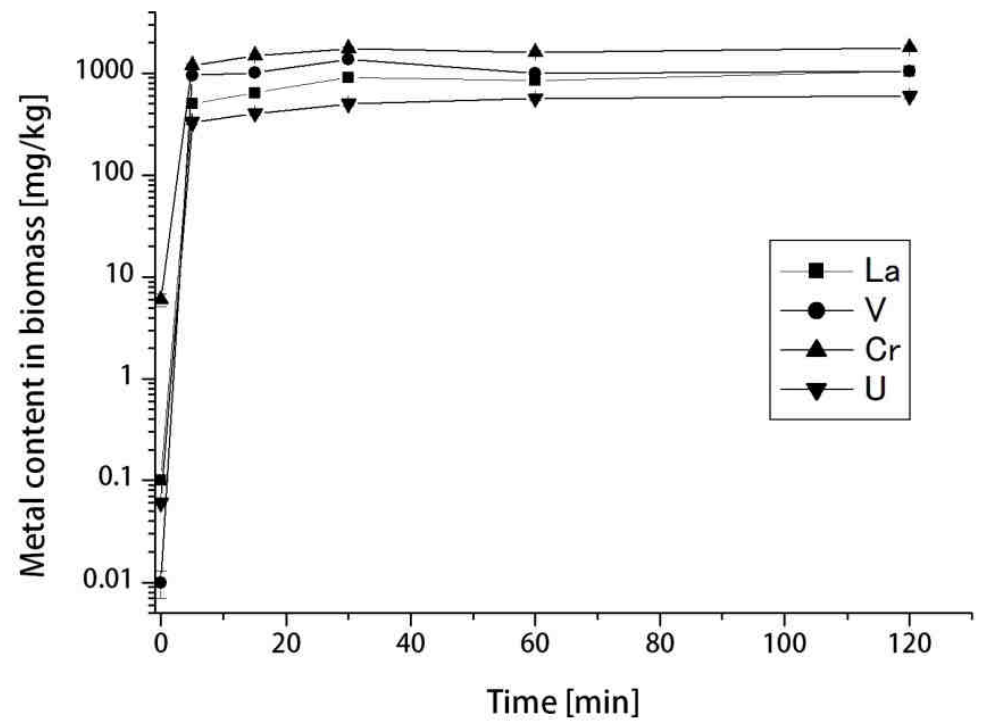

Fig. 4. La, V, Cr, and U concentration in S. platensis biomass as a function of contact time (data for multi-component system)

As it was mentioned above biosorption consists of two-stages: a very rapid initial sorption (0-15 min) followed by a long period of metal uptake (15-120 min). For the rapid stage, the rate of biosorption of metals in single and multi-component systems was calculated (Fig. 5). Obtained results indicated the highest rate of biosorption of chromium in both type of systems. A slight increase of the rate of biosorption of lanthanum in multi-component system was observed. In case of uranium and vanadium the rate of biosorption was more pronounced in multi-component system. 


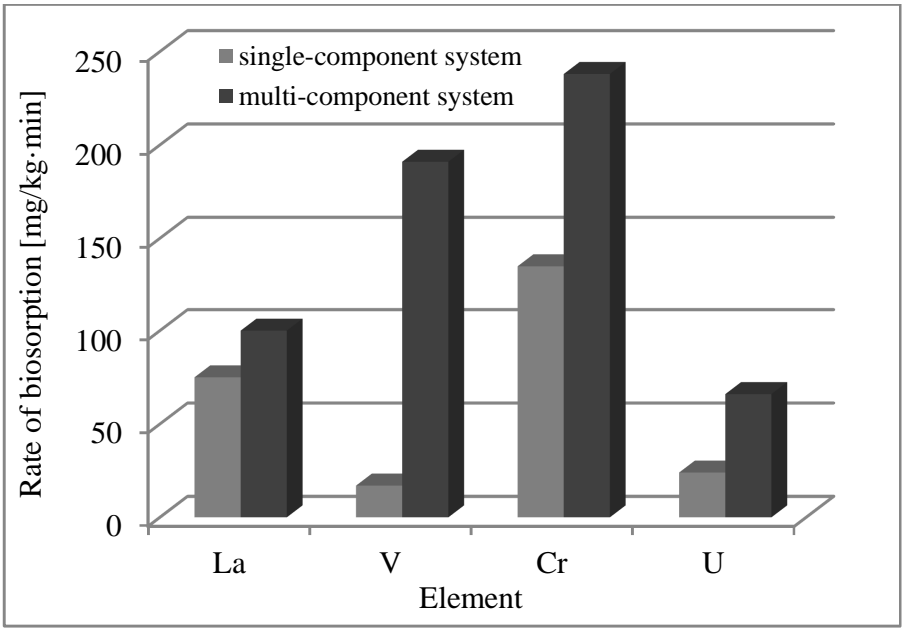

Fig. 5. Rate of biosorption of metals in single and multicomponent systems

Beside rate of biosorption, the distribution coefficient $\left(K_{d}\right)$ for each metal was calculated according to the following formula:

$$
K_{d}=\frac{\left(C_{0}-C_{f}\right) \cdot V}{C_{f} \cdot M}
$$

where $C_{0}$ and $C_{f}$ are initial and final concentrations of metal in the solution $\left[\mathrm{mg} / \mathrm{dm}^{3}\right], V$ is the solution volume $\left[\mathrm{cm}^{3}\right]$ and $M$ is the mass of the sorbent $[\mathrm{g}]$.

$K_{d}$ is very important parameter in sorption processes defined as the ratio of the contaminant concentration associated with the solid to the contaminant concentration in the surrounding aqueous solution when the system is at equilibrium [30]. $K_{d}$ value provides an estimate of the maximum concentration of a metal sorbed to the biomass. $K_{d}$ values obtained in the present work are presented in Table 1 . High $K_{d}$ value indicates the good affinity of chromium ions (sorbate) and the low affinity of vanadium for the spirulina biomass (sorbent) for single component systems. In multi-component system, the significant decrease of $K_{d}$ value for chromium and increase of vanadium was noticed.

Table 1

$K_{d}$ values of sorbent for studied systems

\begin{tabular}{|c|c|c|}
\hline Element & \multicolumn{2}{|c|}{$\boldsymbol{K}_{\boldsymbol{d}}$ value $\left[\mathrm{cm}^{\mathbf{3}} / \mathbf{g}\right]$} \\
\hline $\mathrm{La}$ & single-component system & multi-component system \\
\hline $\mathrm{Cr}$ & 25 & 17 \\
\hline $\mathrm{U}$ & 86 & 34 \\
\hline $\mathrm{V}$ & 10 & 9.2 \\
\hline & 3.3 & 21 \\
\hline
\end{tabular}

High ability of spirulina biomass for metal uptake is influenced by the cell wall composition. Functional groups, such as carboxyl, phosphoryl, hydroxyl and amine are considered the main binding site for metal ions with the formation of metal-ligand surface complexes. In the bioaccumulation process beside metal binding to surface groups the metal ions cross into the cell through special transport systems, by active or passive 
mechanisms [11]. To understand better the nature of functional groups responsible for the metal uptake the FT-IR analysis was performed.

The FT-IR spectrum of control biomass (Fig. 6a) showed several intense characteristic bands in the area $1200-900 \mathrm{~cm}^{-1}$ due to $\mathrm{C}=\mathrm{O}, \mathrm{C}-\mathrm{C}, \mathrm{C}-\mathrm{O}-\mathrm{C}, \mathrm{P}=\mathrm{O}$ groups stretching vibration, and vibration of COO- (vas(COO-) and vs(COO-)), $\mathrm{CH}_{2}$ and $\mathrm{NHC}(\mathrm{O})_{\text {amid }}$ groups located in the area $1600-1300 \mathrm{~cm}^{-1}$. Spectral analysis of V-loaded biomass (Fig. 6b) showed the minimal changes in the FT-IR spectrum. The new band $929 \mathrm{~cm}^{-1}$ can be attributed to $\mathrm{VO}_{3}^{-}$anion. In U-loaded biomass changes in the area $1100 \mathrm{~cm}^{-1}$ were observed. It is suggested what carboxyl and hydroxyl groups are involved in uranium binding. In case of La-loaded biomass the significant shifts in the area of carboxyl vibrations (1600-1300 $\mathrm{cm}^{-1}$ ) for both vas(COO-) and $v \mathrm{~s}(\mathrm{COO}-)$ bands were noticed that indicates binding of $\mathrm{La}$ with $\mathrm{COO}^{-}$that is characteristic for lanthanides. Participation of carboxyl groups in the formation of coordination bonds with chromium was apparent from the spectrum of Cr-loaded biomass.

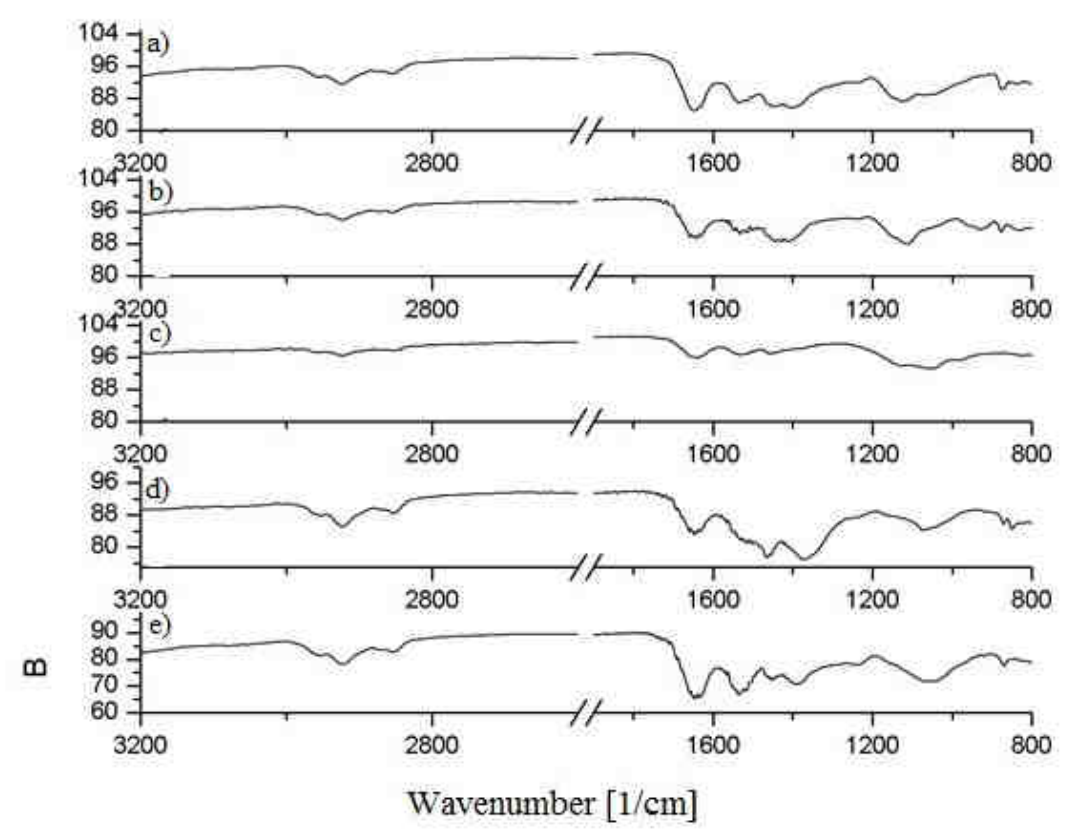

Fig. 6. FT-IR spectra of S. platensis biomass: a) control, b) V-loaded, c) Cr-loaded, d) La-loaded and e) U-loaded

\section{Conclusions}

The uptake of the metals by spirulina biomass occurs differently in single- and multi-component systems. In bioaccumulation experiments in the single-component systems the removal efficiency followed the order: $\mathrm{La}(\mathrm{V})>\mathrm{Cr}(\mathrm{III})>\mathrm{U}(\mathrm{VI})>\mathrm{V}(\mathrm{V})$ and in multi-metal: $\mathrm{Cr}(\mathrm{III})>\mathrm{La}(\mathrm{V})>\mathrm{V}(\mathrm{V})>\mathrm{U}(\mathrm{VI})$. In biosorption experiments spirulina removal efficiency followed the order $\mathrm{Cr}(\mathrm{III})>\mathrm{La}(\mathrm{V})>\mathrm{U}(\mathrm{VI})>\mathrm{V}(\mathrm{V})$ for single-metal systems and in multi-metal system $\mathrm{Cr}(\mathrm{III})>\mathrm{La}(\mathrm{V})=\mathrm{V}(\mathrm{V})>\mathrm{U}(\mathrm{VI})$. 
In bioaccumulation experiments, the difference in the efficiency of metal uptake in single-and multi-component systems was more pronounced in comparison with biosorption experiments.

In the bioaccumulation experiment in multi-metal system the antagonistic effect of uranium and vanadium on lanthanum and chromium uptake was observed, leading to lanthanum and chromium content decrease in comparison with single-metal systems: twice for lanthanum and 1.5 times for chromium. The accumulation of vanadium and uranium significantly increased by 61 and 4 times, respectively compared to the single component system.

The amount of metals accumulated during the bioaccumulation process was 15-40 times higher than in the biosorption experiments. As a result, metal bioaccumulation represents interest from both fundamental and practical points of view. At the same time, spirulina biomass has great nutritive and medical value, thus use of spirulina biomass as bioaccumulator of pollutants is uneconomic. However, spirulina is a beneficial model object and the obtained results can serve as the basis for experiments with other less valuable species of cyanobacteria.

The highest rate of biosorption and $K_{d}$ value were obtained for chromium ions in single-component system. FTIR spectra have revealed that metal capture takes place mainly through binding to $\mathrm{COO}^{-}$and $\mathrm{OH}$ groups.

Spirulina platensis native biomass can be efficiently implemented for metal removal from complex industrial wastewater.

\section{Acknowledgments}

The work was supported by Russian Foundation for Basic Research Grant No 15-33-20069.

\section{References}

[1] Dwivedi S, Srivastava S, Mishra S, Kumar A, Tripathi RD, Rai UN, et al. Characterization of native microalgal strains for their chromium bioaccumulation potential: Phytoplankton response in polluted habitats. J Hazard Mater. 2010;173:95-101. DOI: 10.1016/j.jhazmat.2009.08.053.

[2] Kazy SK, Das SK, Sar PJ. Lanthanum biosorption by a Pseudomonas sp.: equilibrium studies and chemical characterization. Ind Microbiol Biotechnol. 2006;33:773-783. DOI: 10.1007/s10295-006-0108-1.

[3] Jaishankar M, Mathew BB, Shah MS, Murthy TPK, Gowda KRS. Biosorption of few heavy metal ions using agricultural wastes. J Environ Pollut Hum Health. 2014;2:1-6. DOI: 10.12691/jephh-2-1-1.

[4] Lesmana SO, Febriana N, Soetaredjo FE, Sunarso J, Ismadji S. Studies on potential applications of biomass for the separation of heavy metals from water and wastewater. Biochem Eng J. 2009;44:19-41. DOI: 10.1016/j.bej.2008.12.009.

[5] Chojnacka K. Biosorption and bioaccumulation - the prospects for practical applications. Environ Int. 2010;36:299-307. DOI: 10.1016/j.envint.2009.12.001.

[6] Vijayaraghavan K, Yun YS. Bacterial biosorbents and biosorption. Biotechnol Adv. 2008;26:266-291. DOI: 10.1016/j.biotechadv.2008.02.002.

[7] Lesmana SO, Febriana N, Soetaredjo FE, Sunarso J, Ismadji S. Studies on potential applications of biomass for the separation of heavy metals from water and wastewater. Biochem Eng J. 2009;44:19-41. DOI: 10.1016/j.bej.2008.12.009.

[8] Palmieri MC, Volesky B, Garcia O Jr. Biosorption of lanthanum using Sargassum fluitans in batch system. Hydrometallurgy. 2002;67:31-36. DOI: 10.1016/S0304-386X(02)00133-0.

[9] Nazari E, Rashchi F, Saba M, Mirazimi SMJ. Simultaneous recovery of vanadium and nickel from power plant flyash: Optimization of parameters using response surface methodology. Waste Manage. 2014;34:2687-2696. DOI: 10.1016/j.wasman.2014.08.021. 
[10] Tsibakhashvili N, Kalabegishvili T, Mosulishvili L, Kirkesali E, Kerkenjia S, Murusidze I, et al. Biotechnology of Cr(VI) transformation into Cr(III) complexes. J Radioanal Nucl Chem. 2008;278:565-569. DOI: 10.1007/s10967-008-1006-y.

[11] Zinicovscaia I, Cepoi L. Cyanobacteria for Bioremediation of Wastewaters. Switzerland: Springer; 2016. http://www.springer.com/us/book/9783319267494.

[12] Aneja RK, Chaudhary G, Ahluwalia SS, Goyal D. Biosorption of $\mathrm{Pb}$ and $\mathrm{Zn}$ by non-living biomass of Spirulina sp. Indian J Microbiol. 2010;50:438-42. DOI: 10.1007/s12088-011-0091-8.

[13] Michalak I, Zielinska A, Chojnacka K, Matula J. Biosorption of Cr(III) by microalgae and macroalgae: equilibrium of the process. Am J Agric Biol Sci. 2007;2:284-290. DOI: 10.3844/ajabssp.2007.284.290.

[14] Rodrigues MS, Ferreira LS, de Carvalho JC, Lodi A, Finocchio E, Converti A. Metal biosorption onto dry biomass of Arthrospira (Spirulina) platensis and Chlorella vulgaris: multi-metal systems. J Hazard Mater. 2012;30:217-218. DOI: 10.1016/j.jhazmat.2012.03.022.

[15] Kaushik S, Juwarkar A, Malik A, Satya S. Biological removal of Cr(VI) by bacterial isolates obtained from metal contaminated sites. J Environ Sci Health, Part A: Toxic/Hazard Subst Environ Eng. 2008;43:419-423. DOI: $10.1080 / 10934520701795665$.

[16] Use of research reactors for neutron activation analysis. Report of an Advisory Group meeting held in Vienna, 22-26 June 1998. IAEA, Austria, 2001. www-pub.iaea.org/books/iaeabooks/6171/Use-of-ResearchReactors-for-Neutron-Activation-Analysis.

[17] Frontasyeva MV. Neutron activation analysis for the life sciences. Phys Part Nuclei. 2011;42:332-378. DOI: $10.1134 /$ S1063779611020043.

[18] Cecal A, Humelnicu D, Popa K, Rudic V, Gulea A, Palamaru I, et al. Bioleaching of $\mathrm{UO}_{2}{ }^{2+}$ ions from poor uranium ores by means of cyanobacteria. J Radioanal Nucl Chem. 2000;245:427-429. DOI: 10.1023/A:1006707815553.

[19] Merroun ML, Chekroun KB, Arias JM, Gonzalez-Munoz MT. Lanthanum fixation by Myxococcus xanthus: cellular location and extracellular polysaccharide observation. Chemosphere. 2003;52:113-120. DOI: 10.1016/S0045-6535(03)00220-0.

[20] Ortiz-Bernad I, Anderson RT, Vrionis HA, Lovley DR. Vanadium respiration by Geobacter metallireducens: novel strategy for in situ removal of vanadium from groundwater. Appl Environ Microbiol. 2004;70:3091-3095. DOI: 10.1128/AEM.70.5.3091-3095.2004.

[21] Larsson MA, Baken S, Gustafsson JP, Hadialhejazi G, Smolders E. Vanadium bioavailability and toxicity to soil microorganisms and plants. Environ Toxicol Chem. 2013;32:2266-2273. DOI: 10.1002/etc.2322.

[22] Crans DC, Smee JJ, Gaidamauskas E, Yang L. The chemistry and biochemistry of vanadium and the biological activities exerted by vanadium compounds. Chem Rev. 2004;104:849-902. DOI: $10.1021 / \mathrm{cr} 020607$.

[23] Vasilieva SG, Tambiev AK, Sedykh IM, Lukyanov AA, Bannikh LN. The enrichment of biomass of cyanobacteria with vanadium using the cation and anion forms of its compounds. J Trace Elem Med Biol. 2011;25:109-112. DOI: 10.1016/j.jtemb.2011.03.001.

[24] Merroun ML, Raff J, Rossberg A, Hennig C, Reich T, Selenska-Pobell S. Complexation of uranium by cells and S-layer sheets of Bacillus sphaericus JG-A12. Appl Environ Microbiol. 2005;72:5532-5543. DOI: 10.1128/AEM.71.9.5532-5543.2005.

[25] Kalin M, Wheeler WN, Meinrath G. The removal of uranium from mining wastewater using algal/microbial biomass. J Environ Radioact. 2005;78:151-177. DOI: 10.1016/j.jenvrad.2004.05.002.

[26] Shivakumar CK, Thippeswamy B, Krishnappa M. Optimization of heavy metals bioaccumulation in Aspergillus niger and Aspergillus flavus. Int $\mathbf{J}$ Environ Biol. 2014;4:188-195. http://urpjournals.com/tocjnls/13_14v4i2_15.pdf.

[27] Damodaran D, Shetty VK, Balakrishnan RM. Interaction of heavy metals in multimetal biosorption by Galerina vittiformis from soil. Biorem J. 2015;19:56-68. DOI: 10.1080/10889868.2014.939135.

[28] Wong YS, Tam NFY, Wastewater Treatment with Algae. Berlin, Heidelberg: Springer-Verlag; 1998. http://link.springer.com/book/10.1007\%2F978-3-662-10863-5.

[29] Chojnacka K, Chojnacki A, Gorecka H. Biosorption of $\mathrm{Cr}^{3+}, \mathrm{Cd}^{2+}$ and $\mathrm{Cu}^{2+}$ ions by blue-green algae Spirulina sp.: Kinetics, equilibrim and the mechanism of the process. Chemosphere. 2005;59:75-84. DOI: 10.1016/j.chemosphere.2004.10.005.

[30] Understanding variation in partition coefficient, $K_{d}$, values. Review of geochemistry and available $K_{d}$ values for cadmium, cesium, hromium, lead, plutonium, radon, strontium, thorium, tritium $(3 \mathrm{H})$, and uranium. EPA 402-R-99-004B 1999. https:/www.epa.gov/sites/production/files/2015-05/documents/ 402-r-99-004b.pdf. 